\title{
Novas ações para a qualificação nos processos de submissão e publicação de Pesquisas em Geociências
}

\author{
Paulo A. Souza (Editor Chefe) \\ Instituto de Geociências, Universidade Federal do Rio Grande do Sul. Av. Bento Gonçalves, \\ 9500, CEP 91.540-000, Porto Alegre, RS, Brasil (paulo.alves.souza@ufrgs.br)
}

Desde 1972, as diversas comissões editoriais da revista Pesquisas em Geociências tem empregado esforços para qualificar os artigos publicados, de modo a atender à comunidade científica no oferecimento de contribuições que impactem no conhecimento técnicocientífico das áreas relacionadas. Nessa perspectiva, diversas ações foram formuladas, desde a forma de submissão, ao formato e ao tipo de publicação dos artigos (impressa e eletrônica), em atenção às exigências da comunidade científica e às diretrizes estabelecidas pelos distintos órgãos de fomento e avaliação de periódicos.

Nesse sentido, a partir do volume 45 (2018), Pesquisas em Geociências passa a adotar três importantes novidades: processo editorial de submissão e publicação por meio do Sistema de Editoração Eletrônica de Revistas (SEER); divulgação das contribuições na modalidade "publicação continuada" (rolling publishing); e inserção do Digital Object Indentifier System (DOI) em cada artigo.

O Sistema de Editoração Eletrônica de Revistas (Open Journal System) permite realizar todas as etapas editoriais em meio eletrônico, facilitando os processos de submissão, triagem e revisão por pares (peer review), com consequente agilidade nos procedimentos e diminuição do prazo entre submissão e publicação final. Como resultado da implantação do sistema, todos os artigos publicados da revista, desde seu primeiro volume, passam a ter acesso disponibilizado, aumentando a visibilidade das contribuições, fortalecendo a manutenção da memória virtual da revista.

Como resultado de ação coordenada pela Pró-Reitoria de Pesquisa, pelo Programa de Apoio à Edição de Periódicos Científicos da UFRGS e pela Comissão Editorial de Pesquisas em Geociências, todos os artigos publicados pela revista recebem certificação por meio DOI (Digital Object Identifier System) validado pela CrossRef. Trata-se de identificação que visa a localização e direcionamento ao endereço de material bibliográfico na Internet, de modo a garantir a autenticidade e a manutenção dos documentos para as gerações futuras.

Essencialmente visando acelerar o processo de publicação das informações científicas, Pesquisas em Geociências adota o sistema de "publicação continuada" (rolling publishing), em consonância com outras revistas nacionais e internacionais e a tendência cada vez mais crescente de publicações online (vide Scholastica, 2018; SciELO, 2018). Trata-se de forma de publicação em volumes anuais com artigos disponibilizados de forma contínua, publicados conforme forem aprovados, sem a necessidade de fechamento de número.

Todas essas ações qualificam a revista, favorecendo sua visibilidade e as métricas de avaliação, de modo a atender às demandas da comunidade científica.

\section{Referências}

Scholastica. 2018. Why rolling publishing?. Disponível em 05/10/2018 em http://help. scholasticahq.com/customer/portal/articles/2213155-why-rolling-publishing-

SciELO. 2018. Guia para Publicação Contínua de artigos em periódicos indexados no SciELO. Disponível em 05/10/2018 em http://www.scielo.org/local/Image/guiarpass.pdf. 